\title{
A case of hemolytic anemia associated with interstitial lung disease, arthralgia and fever caused by Mycoplasma pneumoniae
}

\author{
David Micarelli, ${ }^{1}$ Gianluca Santoboni, ${ }^{2}$ Michela Tarnani, ${ }^{3}$ Claudio Angrisani, ${ }^{2}$ Alessandra Fiorentini, ${ }^{2}$ Carlo Meschini ${ }^{2}$ \\ ${ }^{1}$ Division of Nephrology and Dialysis, San Giovanni Evangelista Hospital, Tivoli; ${ }^{2}$ Division of Medicine, Belcolle Hospital, \\ Viterbo; ${ }^{3}$ Division of Hematology, Belcolle Hospital, Viterbo, Italy
}

\begin{abstract}
Pulmonary interstitiopathies became the most diagnosed forms of pneumonia in 2020 due to the coronavirus (COVID19) pandemic. The spectrum of interstitiopathies is broad and includes idiopathic diseases and secondary forms. In April 2020, a 36-year-old man was admitted to our department for arthralgias, fever, asthenia, cough, and dyspnea. In January 2020, fever, cough, arthralgias, and asthenia appeared. In April, his general condition worsened with the development of macrohematuria, malaise, and intense asthenia. On admission, the patient presented pale, asthenic, and symptomatic for dyspnea and arthralgias. There was objective joint pain in the small joints of the hands, elbow, and knees with morning stiffness and decreased strength. Computed tomography of the chest documented ground-glass opacities in both lung fields. He performed 2 swabs for severe acute respiratory syndrome-related coronavirus 2, which were negative. On hematochemical examination: immunoglobulin (IgM) $332 \mathrm{mg} / \mathrm{dL}$ and ferritin $700.2 \mathrm{ng} / \mathrm{mL}$. At venous blood smear peripheral venous blood, agglutination of erythrocytes. The serology (IgM) for Mycoplasma pneumoniae was positive with agglutinins in the serum; doxaciclina was started. There was a progressive normalization of hemoglobin levels, cold agglutinins were gradually reduced and were no longer detected at 15 days after the start of treatment. At one month after discharge, pulmonary function had fully recovered, and the picture of hemolytic anemia was resolved.
\end{abstract}

Correspondence: David Micarelli, Nephrology and Dialysis Unit, San Giovanni Evangelista Hospital, via A. Parrozzani, snc 00019 Tivoli, Italy. E-mail: david.micarelli@aslroma5.it

Key words: Interstitial lung disease; hemolytic anemia; $M y$ coplasma pneumoniae; agglutinin.

Contributions: GS and DM equally contributed at the manuscript. They wrote the paper, treated and followed the patient, and revisited the case. MT reviewed the Blood smear. CA and $\mathrm{CM}$ were the physicians of the patient and completed data and helped in writing the draft. All authors read and signed the final paper.

Conflict of interests: the authors declare no potential conflict of interests.

Informed consent: informed consent was obtained from all individual participants included in the study. Additional informed consent was obtained from all individual participants for whom identifying information is included in this article.

Received for publication: 1 November 12020.

Revision received: 15 December 2020.

Accepted for publication: 30 December 2020.

This work is licensed under a Creative Commons Attribution NonCommercial 4.0 License (CC BY-NC 4.0).

${ }^{\circ}$ Copyright: the Author(s), 2021

Licensee PAGEPress, Italy

Italian Journal of Medicine 2021; 15:111-114

doi:10.4081/itjm.2021.1416

\section{Introduction}

The interstitial lung diseases (ILDs) are a heterogeneous group of disorders classified together because of similar clinical manifestations and imaging findings. ${ }^{1}$ ILDs spectrum is broad and includes idiopathic and secondary forms. The development of secondary ILDs can be associated with a broad range of systemic diseases (rheumatic diseases, uremia, a congenital inborn error of metabolism), exposures to inhaled inorganic and organic dust, infectious agents, and drugs. Correct diagnosis is fundamental, and the treatment choices and prognosis are different among all the different types of ILD. Interstitial lung disease became the most diagnosed type of lung disease in 2020 because of the eruption of coronavirus 2019 (COVID19) as a breakthrough of severe acute respiratory syndrome-related coronavirus 2 (SARS-CoV-2) in Wuhan. ${ }^{2}$ Since then, there has been an important shift in epidemiology, etiology, and outcome of ILDs.

Here we report a really uncommon case of a young man with cough, fatigue, fever, and arthralgia.

\section{Case Report}

In April 2020, a 34-year-old Caucasian man was admitted to our ward because of arthralgia, fever, fa- 
tigue, cough, and dyspnea. The patient had been well until January 2020 when suddenly appeared highgrade fever, cough, arthralgia, fatigue. His general practitioner prescribed some laboratory tests with normal results. Acetaminophen and some course of antibiotic therapy (penicillin) were administered with slight improvement. In April, his general condition fell, and he developed dark urine, malaise, intense fatigue, and a new flare of fever, chills, and productive cough. He presented to our hospital. On admission, the patient was pale, asthenic and was symptomatic for dyspnea and arthralgias. Joint pain of the small joints of the hands, wrist, and knees was present, along with morning stiffness and decreased grip strength. Past clinical history was negative. Upon physical examination, blood pressure was 110/70 $\mathrm{mmHg}$, pulse rate was 100/minute, respiratory rate was 22 breaths $/ \mathrm{min}$, and the temperature was $38.7^{\circ} \mathrm{C}$. Chest examination showed bilateral fine, moist rales and sporadic dry rales. Chest X-ray revealed opacity in bilateral lower lobes, while abdominal ultrasound was normal. Lung computed tomographic (CT) scan revealed mediastinal and hilar lymphadenopathy, diffuse centrilobular micronodules, and patchy opacities in both lung fields with mild thickening of bronchial walls. In suspect of COVID-19, he was tested with two consecutive nasopharyngeal swab tests (polymerase chain reaction, confirming SARS-CoV-2 infection), but tests were negative. Laboratory testing is reported in Table 1. Liver profile, kidney profile, and coagulation studies were within normal limits. Serum electrophoresis revealed no abnormalities. Serum C3, $\mathrm{C} 4$, and total $\operatorname{IgA}$ and $\operatorname{IgG}$ levels were normal, where IgM was $332 \mathrm{mg} / \mathrm{dL}$. Ferritin levels were 700.2 $\mathrm{ng} / \mathrm{mL}$. Microscopic examination of the peripheral blood smear (Figure 1) revealed red cell agglutination. Direct Coombs test and cold agglutinins were positive. Additionally, ANA, ANCA, ENA, rheumatoid factor, anti-HIV, anti-hepatitis $B$ virus, anti-hepatitis $C$ virus, Epstein Barr virus, Cytomegalovirus, and Parvovirus B19 were absent. Mycoplasma pneumoniae serology was positive, with specific immunoglobulin $\mathrm{M}$ detected in serum samples.

When the diagnosis of $M$. pneumoniae infection was established, he was also started on doxycycline. Hemoglobin levels gradually normalized. Cold agglutinins gradually decreased and are not more detected within 15 days. One month after hospital discharge, pulmonary function was fully recovered.

\section{Discussion}

Landsteiner first described cold agglutinins in 1903. . $^{3-6}$ Their pathological action against red blood cells and blood vessels was later described by Clough and Iwai. ${ }^{78}$ In 1953 Schubothe called this disease cold agglutinin disease (CAD). ${ }^{9}$

M. pneumoniae causes up to $40 \%$ of cases of community-acquired pneumonia and as many as $18 \%$ of

Table 1. Laboratory parameters of the patient.

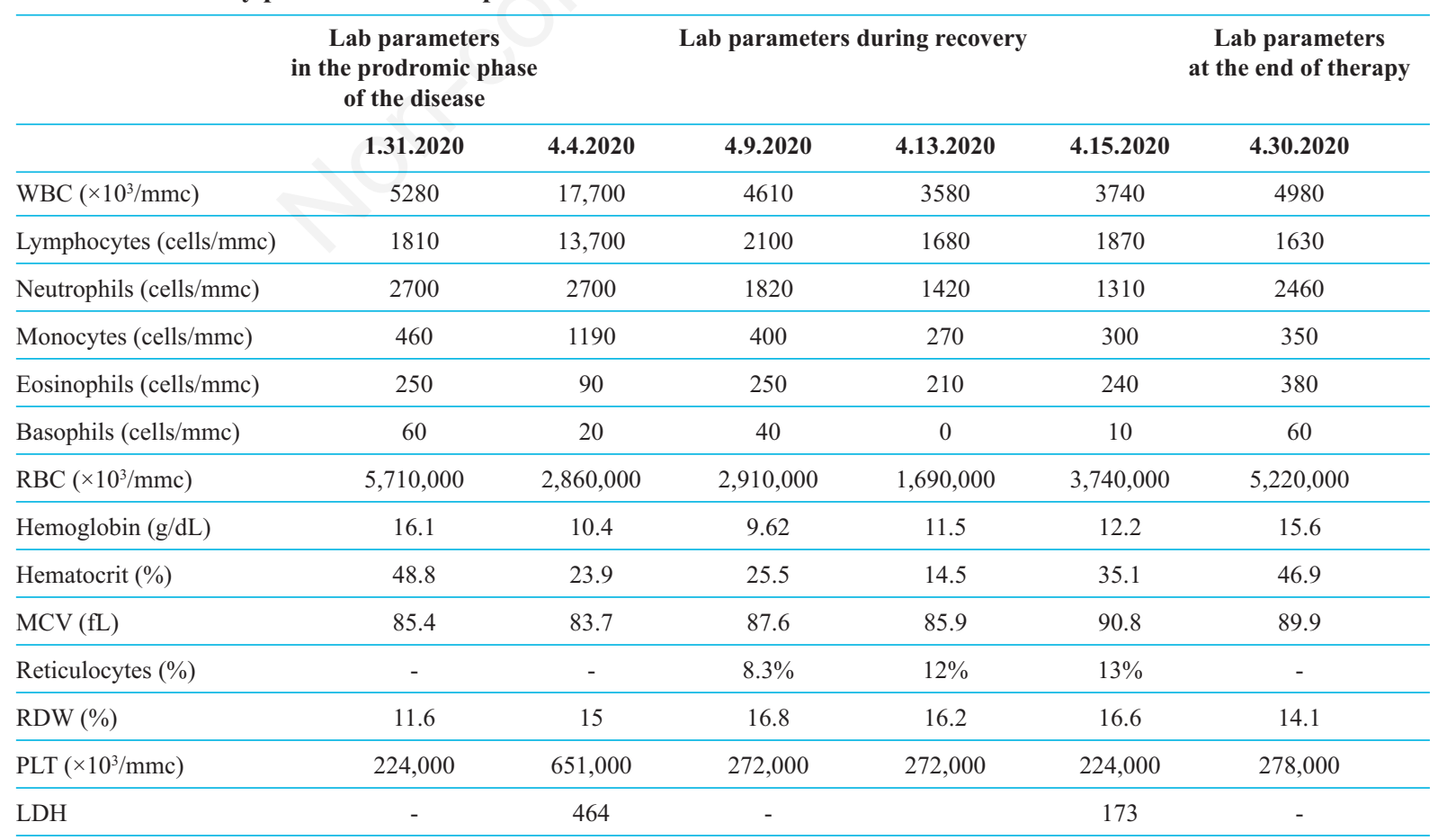

WBC, white blood cells; RBC, red blood cells; MCV, mean corpuscular volume; RDW, red blood cells distribution width; PLT, platelets; LDH, lactate dehydrogenase. 
cases requiring hospitalization in children. About 25\% of patients may experience extrapulmonary complications. Autoimmune reactions have been suggested to be responsible for many of these manifestations. CAD is characterized by an auto-antibody ${ }^{10}$ that can agglutinate red blood cells (RBCs) at temperatures lower than that of the body and subsequently activate the complement system responsible for the lysis of RBCs.
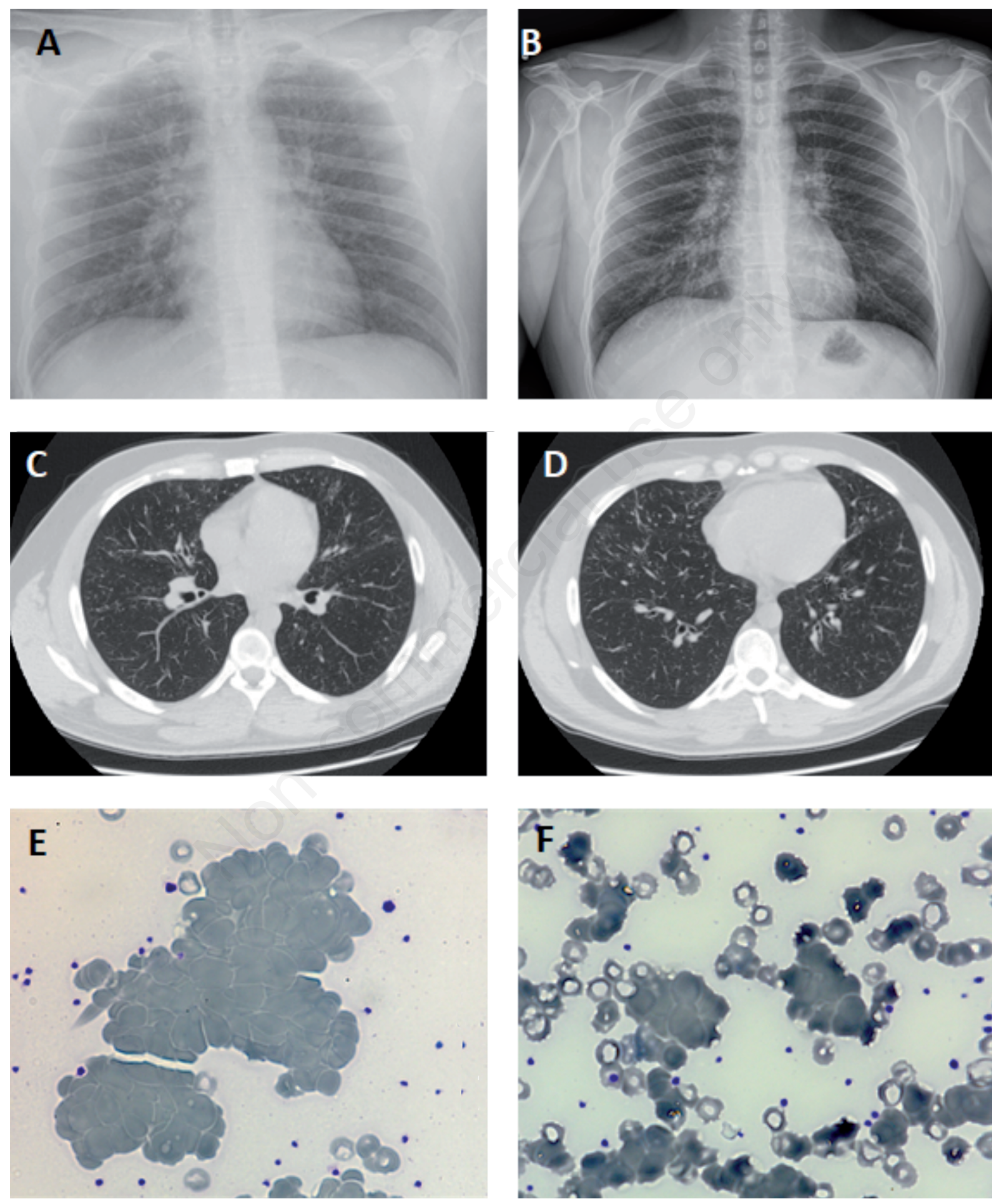

Figure 1. Chest X-ray of the patient. A) Small opacity in right upper lung and large dense opacity in the left lung on day 4 after onset. B) Chest X-ray after therapy with clear lung field on day 27. C and D) Computed tomography scan showed Bilateral opacities progressed with left lung consolidation on day 7. E and F) Blood smear showed red cell agglutination. E: $4^{\circ} \mathrm{C}$ image of blood smear showed agglutination of red blood cells (RBC); and F) at $37^{\circ} \mathrm{C}$ showed normal distribution of RBC. 
Cold agglutinin antibodies are mainly specific for the RBCs membrane systems, ${ }^{11}$ and their production can be stimulated by M. pneumonia or by lymphoproliferative disorders. The auto-antibody involved is usually an IgM, which can agglutinate $\mathrm{RBCs}$ at temperatures of between 0 and $5^{\circ} \mathrm{C}$. Complement activation generally occurs between 20 and $25^{\circ} \mathrm{C}$ but is also possible at normal body temperature. Hemolytic anemia is recognized as a rare but severe complication of Mycoplasma infection. Our patient presented with anemia due to intravascular hemolysis accompanied by articular involvement. This particular effect has been described previously with infections by $M y$ coplasma (also known as hemoplasma in this setting) via induction of complement receptor 1 expression on erythrocytes. ${ }^{3}$ Complement receptor 1 mediates immune adherence, a fundamental event for destroying microbes and initiating immunological responses. Hemoplasma determines hemolytic anemia mainly through complement-mediated cell lysis but also via direct damage to the erythrocytes membrane and phagolysis by the mononuclear phagocyte system. ${ }^{4}$ Besides, some of Mycoplasma's protein components share peptide sequence similarities with complement regulatory proteins and, therefore, they can modulate human complement activation. ${ }^{5}$

The first-line treatment can be either macrolides or tetracyclines; we choose tetracyclines for the patient's history of adverse effects developed with azithromycin. In our case, the response to antibiotic therapy was complete and other therapies for non-respiratory tract disease manifestations of CAD, as immunosuppressive agents, immunomodulatory therapies, or plasmapheresis, were not necessary.

\section{Conclusions}

We showed a case of ILD due to M. pneumoniae infection complicated by articular involvement and immune hemolytic anemia due to CAD. Primarily when the imaging findings are associated with other extrapulmonary conditions, M. pneumoniae should be taken into differential diagnosis in patients suspected of COVID-19. In our case, secondary autoimmune hemolytic anemia was the trigger for correct diagnosis.

\section{References}

1. Travis WD, Costabel U, Hansell DM, et al. An official American Thoracic Society/European Respiratory Society statement: Update of the international multidisciplinary classification of the idiopathic interstitial pneumonias. Am J Respir Crit Care Med 2013;188:733-48.

2. Zhu N, Zhang D, Wang W, et al. A novel coronavirus from patients with pneumonia in China, 2019. N Engl J Med 2020;382:727-733.

3. Congbin Y, Aibin L, Congli Y, et al. Overexpression of complement receptor type I (cr1, cd35) on erythrocytes in patients with hemoplasma infection. Microbiol Immunol 2010;54:460-5.

4. Smith BO, Mallin RL, Krych-Goldberg M, et al. Structure of the $\mathrm{c} 3 \mathrm{~b}$ binding site of $\mathrm{cr} 1(\mathrm{~cd} 35)$, the immune adherence receptor. Cell 2002;108:769-80.

5. Kikkawa S, Matsumoto M, Sasaki T, et al. Complement activation in mycoplasma fermentans-induced mycoplasma clearance from infected cells: probing of the organism with monoclonal antibodies against m161ag. Infect Immun 2000;68:1672-80.

6. Landsteiner K. Über beziehungen zwischen dem blutserum und den korperzeller. Munch Med Worchenschr 1903;50:1812.

7. Clough MC, Richter IM. A study of an autoagglutinin occuring in a human serum. Johns Hopkins Hosp Bull 1918;29:86.

8. Iwai S, Mei-Sai N. Etiology of Raynaud's disease. Jpn Med World 1926;6:345.

9. Schubothe H. The cold hemagglutinin disease. Semin Hematol 1966;3:27.

10. Petz LD, Garraty G. Acquired immune hemolytic anemias. New York: Churchill Livingstone 1980. pp 63-76.

11. Geoff D. Human blood groups. London: Blackwell Science, Ltd.; 1995. pp 53-61. 